\title{
An overview on enterprise networks and company performance
}

\author{
James Onuche Ayegba, Zhou Lu Lin
}

\section{A B S T R A C T}

Objective: This study elucidates the empirical review of enterprise networks on company performance.

Research Design \& Methods: Enterprise networks are also referred to as corporate network which is among the major pillars of any business. The importance of enterprise networks cannot be far-fetched from or beyond its evolving supports through encapsulation of software applications, databases, for the purpose of achieving fully business goals.

Findings: The empirical covers the essence of enterprise networks, reasons for enterprise networking in company performance, formation of enterprise network, the management of enterprise network, and the interplay between enterprise network and company performance. It was concluded in the previous studies that performance of enterprise networks could entail enterprise network survival, profit maximization, sales maximization, return on investment, sales growth and a number of employees.

Contribution \& Value Added: Hence, it is affirmed in this study that enterprise network performance is a set of financial and nonfinancial indices which offer information on the extent of achieving aim, objectives and better outputs of the enterprise network.

\begin{tabular}{ll}
\hline Article type: & research paper \\
& Enterprises growth; enterprise network; technology innovation; en- \\
& terprise efficiency; enterprise performance
\end{tabular}

JEL codes: L25, L1, H21,Q55

\section{Suggested citation:}

Ayegba, J.O., \& Lin, Z.L. (2020). An overview on enterprise networks and company performance. International Entrepreneurship Review (previously published as International Entrepreneurship / Przedsiębiorczość Międzynarodowa), 6(2), 7-16. https://doi.org/10.15678/IER.2020.0602.01

\section{INTRODUCTION}

An enterprise network is an enterprise's communications backbone that creates connection between computer and devices among enterprise's workgroup and department's networks; helps facilitate accessibility data and give knowledge to its use. This networking help reduces communication protocols, device interoperability and facilitate system, es- 
pecially important in view of the decentralization trends in today's organizations where the network must play a unifying and integrating role, as well as improved external and internal firm data management. (Wynekoop et al., 2001)

An enterprise network can also be called corporate network. It is one of the pillars of a business: it helps support evolving and existing applications, databases, while helping to fully business goals reliably, and be adaptable and accessible. Organizations' applications development problems are not as great as the infrastructure problems (Kern et al., 2000). An enterprise network is an enterprise's relay system that helps related devices and connect computers across departments and workgroup networks, to facilitate easy access to data and give a good insight.

Enterprise networking facilitate system that eases communication protocols and systems interoperability, as well as increase external and internal enterprise data flow management (Techopedia.com) The various companies which implement the enterprise network system are Apple, Amazon, Arista, and Citrix (Networkworld.com). The system of an enterprise network support thousands of users all across the company's at the diverse location geographically. It may involve various switches, routers, and server. Each location system looks simply, but the complexity of the increasing network even as the systems are linked together in the topology. Enterprise network system increases the data transmission rate across the globe. The key requirement of the enterprise network system is performance (bandwidth, delay and jitter) and security (access and transmission).

Over the years, business enterprises have been witnessing unparalleled and exceptional degree of transformation, conversion, intense and forceful competition, and tumultuous environment globally. These transformations emanate as a result of market fragmentation, changing technology, dynamic management, the convergence of different business enterprises, supplier attitudes, changing customer demands, changing customer expectations, reduced life cycle of product, etc. which have direct and indirect implication on business performance. According to Ahmad et al. (2014), business enterprises are encountering significant challenges because of the dynamic attributes of business enterprise itself, the market, and environmental circumstances.

In fact, in the current and widespread competition and challenging economic circumstances, a practicable, feasible, dynamic, and forceful enterprise networks is vital to the economic improvement of a particular country (Zahra et al., 2006). In the same vein, Ahmad and Pirzada (2014) noted that enterprise networks are known to be the mechanism of growth and development which has significant roles in the establishment of laudable economic development.

It is believed that this approach is capable of giving a plausible result and the result will be added to the body of literature. performance of enterprise networks for the growth and fortification of the economy. Zhu et al. (2013) noted that however, enterprise networks are faced with many challenges and uncertainties in the competitive business environment and inauspicious circumstances in recent years. These have resulted into the challenges of superior and improved business performance.

According to Kayode (1989) enterprise networks are the heart of any economy. Its importance to the growth and survival of the economy cannot be overemphasized. Enterprise networks play a crucial role in the economy of most countries. In the study, it was stated that the proceeds are oftentimes products offered to customers that result into 
profit making when pooled together by the owners of enterprises networks. Obisi (2013) in his study, it was added that the enterprise networks all over the world would continue to be the engine of development and industrialization.

Recently, much attention has been paid to the lack of knowledge about how information systems are actually developed and how system development methodologies are adapted or used (Adeniran \& Olorunfemi, 2020; Wynekoop et al., 2001) little focus has been given to networking using wide area networks (WANs) are actually designed (or redesigned) or to the methods used to do so.The aim of the study is to elucidate the empirical review of enterprise networks on company performance as it is among the major pillars of any business.

\section{LITERATURE REVIEW}

\section{The Essence of Enterprise Network}

Enterprise network can be referred to the virtual, physical and logical design of a network, and how the various software, hardware and protocols work together to transmit data. When it comes to enterprise networking, every organization has several and divers' needs, and in the digital era of which has led to several changes, modern enterprises are investing and depending more on software-based solutions to enable effective network architecture, automation and design. Firms of different sizes are starting to avoid exuberant fee network management tools cost. No doubt the tools have essential functionality, but are it justifiable to spend so much on them?

In our hyper-connected world, a stable, reliable network is regarded as a necessity, and the consequences of an unreliable network are only getting more severe. According to Gartner, the estimated cost of a downtime in network is 5,600 USD per minutes, which can get much higher for technology-dependent organizations. As the firms networking architectures grow more complex, many organizations then find it difficult to keep up. But with several networking solutions the process can be simplify, with solutions like automated campus, unified wired/wireless infrastructures, and agile data centre networking solutions.

\section{Company Performance}

The concept of performance of a business enterprise network is based on the premise that an organization is the voluntary association of dynamic assets, as well as physical, human, and capital resources, for the aim of realizing a shared purpose (Carton, 2004). Performance is one of the most applicable variables in strategic management; a construct commonly used as the final dependent variable in various fields. It is believed that the quintessence of performance is the value creation; therefore, value creation is defined by the resource provider as the indispensable tool for general performance measures for any organization (Monday et al., 2015).

Performance measurement is indispensable to enable managers evaluate the unambiguous actions of their enterprise networks, and how the enterprise networks perform over time (Sabina, 2009). The concept of performance has been widely examined by different authors from different perspectives, and consequently there is no consensus on a particular definition. According to Gavrea et al. (2011), organization will be able to survive 
if and only if performance is assessed. Performance measurement is the heart of any organization. A business organization could measure or determine its performance by adopting the financial and non-financial measures.

Moullin (2003) defines performance in terms of how well an organization is managed and the value the organization delivers to customers and other stakeholders. In the view of Laitinen (2002), performance is the ability of an object to produce results in a dimension determined a priori, in relation to a target". Jamil \& Mohamed (2011) also define performance as the measure of how managers utilize resources of the organization in an effective and efficient manner to accomplish goals and satisfy stakeholders while Richard et al. (2009) also noted performance as real output against expected output which they categorized into financial performance, product market performance and shareholders return. Adeniran \& Olorunfemi (2020) identifies performance as the reflection of how the organization uses its resources in such a way that will make certain the accomplishment of its set objectives.

\section{Reasons for Enterprise Networking in Company Performance}

The Enterprise Network System would function efficiently throughout its span of service without any compromises such as lags, delays and jitters. It follows protocols which reduces the downtime which is very essential for any enterprise to function profitably. Enterprise Network also help facilitates communication between two clients and is also responsible for an exponential growth of the business of the firm.

The use of VLAN (Virtual Local Area Network) provides the network an idea of confinement of network reduction of broadcast traffic. And the transfer of messages is done at a faster rate using EIGRP (Enhanced Interior Gateway Routing Protocol) routing protocol.SSH (Secure Shell) is also use by companies to provide a secure remote access to a network and also an ease for administration throughout the system.

For the Networking to work well it needs an efficient handler for the enterprise network system since it is complex in structure. Majorly large business embraces this for their performance because its cost of implementing the networking across the different zone can be high. This can still lack robustness if the core file server of a network fails, it might lead to failure of the whole network.

\section{Enterprise Network Formation}

According to Pittaway et al. (2004), there are two explanations for the formation of business networks. The first explanation focuses on a resource view according to which firms form network relationships to obtain access to technical or commercial resources (Ahuja, 2000). The second explanation is on a theory in which prior relationships facilitate linkage formation (Ahuja, 2000).In addition to these two primary explanations, prior studies have found several other positive implications of networking (Pittaway et al., 2004).

For instance, network relationships can provide emotional support for entrepreneurs who assume risks and thus increase the desires of entrepreneurs to continue conducting business (Hoang \& Antoncic, 2003). They further noted that entrepreneurs can also use networks to gather information, ideas, or advice. More importantly, small business owners can gain access to research and development (R\&D) outsourced by major firms; establish joint R\&D ventures; and establish other relationships, such as marketing or manufacturing relationships. In conclusion, networks are formed to gain access to resources and support. 


\section{Management of Enterprise Network}

Enterprise network management is a key aspect of networking, and the types of network management affect the types of network ties. When there is a relationship between actors evolves from a weak tie to a strong tie over time, the actors within this relationship eventually trust one another, and the relationship provides an effective channel for information flow (Larson, 1992).

Uzzi (1997) finds that trust is especially likely to develop when both sides devote additional effort (typically voluntary effort) to a relationship. This additional effort is typically described as 'favours', as official reciprocity (e.g., contracts) cannot be observed. In addition, Uzzi (1997) alleges that a trust-managed relationship offers access to otherwise unavailable resources that can increase competitiveness. Information flow that is based on trust has been shown to be an integral aspect of a strong, long-term inter-firm relationship (Siwangaza et al., 2014). Reliance on strict contracts rather than trust between actors has been shown to depend on the culture and the institutional context in which firms operate.

In the study of Larson (1992), a typology of three distinct governance mechanisms for relationships between organisations was proposed: shared governance, a lead organisation-governed mechanism, and a system that is controlled by NAO (Network Administrative Organisation). The shared governance method assumes that the organisations in a network manage the operation of the network by making both strategic and operational decisions together; therefore, no formalised governance body exists. Lead organisationgoverned networks typically have one larger or more powerful firm that operates as the lead or hub firm. All of the firms in such a network share a common purpose, but only the lead firm may have the resources or legitimacy that is required to serve in the lead role in the network. NAO-governed networks are comparable to lead organisation-governed networks, as both types of networks are managed by one central organisation. In contrast with lead organisation governance, the controlling organisation in NAO-governed networks has only a pure governance role.

Additionally, Provan et al. (2004) observe that the NAO model is common in some European countries (e.g., Germany) because this type of network is believed to simulate interactions between the public sector and the private sector in clusters or networks. The study of Prashantham \& Dhanaraj (2010) review innovation and networks, and concluded that enterprises have the competence to manage their networks, but the level of competence varies widely across enterprises. Additionally, the extent to which firms have access to new opportunities is connected to their existing networks and participation in those networks.

\section{MATERIAL AND METHODS}

This method adopted in this study was solely on empirical review. This enhances the consolidation of research facts from earlier studies on the subject matter.

\section{Empirical Review of Enterprise Network and Company Performance}

There has been no systematic study of how enterprise networks correlate to company performance (and little coverage in the trade covers). Although telecommunications as evolve and naturally outgrowth this function in businesses, it is not necessarily sound in 
today's decentralized and changing business environment (Segars et al., 2007). Activities observed by Matias \& Andrade (2012), enterprise networking connection can be felt on a company's performance and the internalization of the enterprise. Matias explained that the question of whether the concept of network activity should be divided into two separate factors: consistently high network activity; and increasingly high network activity.

Consistently high network activity describes long-term embedded relationships, and increasingly high network activity describes the importance of the creation of new relationships and ties. The first factor describes a situation in which network activity does not substantially evolve. By contrast, the second factor describes a process in which the network size increases as the needs of the focal actor evolve, and the increase counteracts decreases in social capital.

Prashantham \& Dhanaraj (2010) specifically emphasise is the importance of networking when a firm internationalises its activities. Moreover, Wright et al. (2007) imply that entrepreneurs must establish network connections to secure access to appropriate resources, knowledge, and learning to form 'a positive platform for internationalisation'. In addition, Andersson \& Wictor (2003) suggest that entrepreneurial networks are essential assets for ventures that are attempting to internationalise their operations. Furthermore, Ojala (2009) proposes that knowledge-intensive SMEs form new network relationships or utilize existing relationships when extending their market presence to new distant markets. In conclusion, the above discussion suggests a positive connection between activity in entrepreneurial networks and internationalisation. Hence, there is expected positive connection between network activity and enterprise's internationalisation.

The design and management of enterprise networks is technologically complex, and it observed that only a few people can understand even a single networked information system. Because of the complexity and enormity of the task, even fewer people would be able to study more than one such system, resulting in a poor understanding of what practices will reduce or eliminate design and implementation errors or allow networked systems to be designed to offset these errors (Macey \& Schneider, 2008).

The planning and control of many enterprise networks are entangled with the challenge to perk up their performance and pact with the changing dynamics of competitive arena (Waithaka, 2016). Enterprise networks have a crucial role in the daily living, and successful enterprise networks are germane ingredients for developing nations like $\mathrm{Ni}$ geria. Practitioners and academics endeavour to be aware of and explain the differences in enterprise network performance in the face of the complexity of the market, competitive pressures and uncertainties. Enterprise networks must be able to adapt with the increasingly challenges from the business environment, in order to boost their capacity to adapt (Gavrea et al., 2011). The concept of performance of a business enterprise network is based on the premise that an organization is the voluntary association of dynamic assets, as well as physical, human, and capital resources, for the aim of realizing a shared purpose (Barney, 1995; Carton, 2004).

According to Cho \& Pucik (2005)Richard et al. (2009), enterprise network performance is one of the most applicable variables in strategic management; a construct commonly used as the final dependent variable in various fields. It is believed that the quintessence of performance is the value creation, therefore, value creation is defined by the resource provider as the indispensable tool for general performance measures for any organization 
(Monday et al., 2015). The concept of enterprise network performance has been widely examined by different authors from different perspectives, and consequently there is no consensus on a particular definition. According to Gavrea et al. (2011), continuous performance is the heart of any organization which is established only through performance, and the organizations are able to survive. A business organization could measure or determine its performance by adopting the financial and non-financial measures.

According to Olabisi, Olagbemi \& Atere (2013) enterprise network's performance is complex, and is characterized by the enterprise network's ability to create acceptable outcomes and actions. According to Adeleke, Ogundele \& Oyenuga, (2008), an enterprise network is said to achieve an effective performance if it makes use of its resources to attain high level of performance. They also noted that enterprise network is that a business enterprise network that is effective if it attains its sales or market share goals which depend on efficiency. Moullin (2003) defines enterprise network performance in terms of how well an organization is managed and the value the organization delivers to customers and other stakeholders. In the view of Laitinen (2002), enterprise network performance is "the ability of an object to produce results in a dimension determined a priori, in relation to a target". Jones and Goerge (2006) also define performance as the measure of how managers utilize resources of the organization in an effective and efficient manner to accomplish goals and satisfy stakeholders while Richard et al. (2009) also noted performance as real output against expected output which they categorized into financial performance, product market performance and shareholders return.

\section{CONCLUSIONS}

This study elucidates the empirical review of enterprise networks on company performance. Enterprise networks are also referred to as corporate network which is among the major pillars of any business. Performance is an approach that is used in assessing the progress made towards achieving goals, identifying and adjusting factors that will reduce the progress of the organization in the environment. Enterprise network's performance is complex and is characterized by the enterprise network's ability to create acceptable outcomes and actions. Organization achieves its goals by transforming inputs into output at the lowest possible costs. An organization that has the tendency or strength of doing this can be linked to be performing. From the empirical review, it was found that the significance of enterprise networks cannot be far-fetched from or beyond its evolving supports through encapsulation of software applications, databases, for the purpose of achieving fully business goals.

It was concluded that enterprise performance could enhance enterprise network survival, profit maximization, sales maximization, return on investment, sales growth and a number of employees. This study perceives enterprise network performance as a set of financial and nonfinancial indices which offer information on the extent of achievement of aim, objectives and results of the enterprise network. This study is limited to the whole of enterprise network and company performance. Future studies may breakdown the indicators of enterprise networks and the indicators of company performance for simplicity. 


\section{REFERENCES}

Adeleke, A., Ogundele, O. J. K., \& Oyenuga, O. O. (2008). Business Policy and Strategy, (2 ${ }^{\text {nd }}$ Ed). Concept Publications.

Adeniran, A.O., \&Olorunfemi, S.O. (2020). The Essence of Knowledge Management in the Air Transportation Sector. International Journal Human Capital Urban Management, 5(2), 175-186.

Ahmad, N., Othman, S.N., \&Lazim, H.M. (2014). A Review of Technological Capability and Performance Relationship in Manufacturing Companies. International Symposium on Technology Management and emerging technologies (ISTMET 2014).

Ahmad, Y., \& Pirzada, D. S. (2014). Using Analytic Hierarchy Process for Exploring Prioritization of Functional Strategies in Auto Parts Manufacturing SMEs of Pakistan. SAGE Open, 1-12. DOI: $10.1177 / 2158244014553560$

Andersson, S., \& Wictor, I. (2003) Innovative Internationalization in New Firms: Born Global-The Swedish Case. Journal of International Entrepreneurship, 1, 249-275. http://dx.doi.org/10.1023/A:1024110806241

Ahuja, G. (2000). Collaboration Networks, Structural Holes, and Innovation: A Longitudinal Study. Administrative Science Quarterly, 45(3): 425-455.

Barney, J. B. (1995). Enterprise Resources and Sustained Competitive Advantage. Journal of Management, 17, 99-120.

Bowen, F.E., Rostami, M., \& Steel, P. (2010). Timing is Everything: A Meta-Analysis of the Relationships between Organizational Performance and Innovation. Journal of Business Research, 63(11), 1179-1185.

Carton, R.B. (2004). Measuring Organizational Performance: An Exploratory Study. Unpublished PhD Thesis, University of Georgia, Athens.

Cho, H., \& Pucik, V. (2005). Relationship between Innovativeness, Quality, Growth, Profitability and Market Value. Strategic Management Journal, 26, 555-575. http://dx.doi.org/10.1002/smj.461

Gavrea, C., Ilies, L., \&Stegerean, R. (2011). Determinants of Organizational Performance: The Case of Romania. Management and Marketing Challenges for the Knowledge Society 6(2), 285-300.

Hashim, N.A.B., Raza, S., \&Minai, M. S. (2018). Relationship between Entrepreneurial Competencies and Small Firm Performance: Are Dynamic Capabilities the Missing Link? Academy of Strategic Management, Journal, 17, 1-10.

Hoang, H., \& Antoncic, B. (2003). Network-based Research in Entrepreneurship: A Critical Review. Journal of Business Venturing, 18(2), 165-187.

Jamil, C. M., \& Mohamed, R. (2011). Performance Measurement System (PMS) In Small Medium Enterprise (SMES): A Pratical Modified Framework. World Journal of Social Sciences, 1(3), 200- 212.

Kayode, M.O. (1989). Nigeria since Independence: The first 25 years. Heinemann Books Ltd.

Kern, H., Galup, S.D., \& Nemiro, G. (2000). IT Organization. Upper-Saddle River, NJ: Prentice Hall.

Laitinen, E.K. (2002). Financial Rating of European Technology Companies: An International Comparison. Journal of Business Finance and Accounting, 29(7-8), 871-901. https://doi.org/10.1111/1468-5957.00454

Larson, A. (1992). Network Dyads in Entrepreneurial Settings: A Study of the Governance of Exchange Relationships. Administrative Science Quarterly, 37,76-104.

Macey, W.H., \& Schneider, B. (2008). The Meaning of Employee Engagement. Industrial and Organizational Psychology, 1, 3-30. http://dx.doi.org/10.1111/j.1754-9434.2007.0002.x 
Matias, M., \& Andrade, C. (2012). The Interplay of Gender, Work and Family in Portuguese Families. Work, Organization, Labour and Globalization, 6(1), 11-26.

Monday, J.U., Akinola, G.O., Ologbenla, P.,\&Aladeraji, O.K. (2015). Strategic Management and Enterprise Performance: A Study of Manufacturing Companies in Nigeria. European Journal of Business and Management, 7(2), 162-171.

Moullin, M. (2003). Defining Performance Measurement. Perspectives on Performance, 2(1), 3-15.

Obisi, C. (2013). Nigerian Business Environment Daunting: Challenges and Suggested Solutions. British Journal of Economics, Finance and Management Sciences, 7 (1), 47-52

Ojala, A. (2009). Internationalization of Knowledge Intensive SMEs: The Role of Network Relationships in the Entry to a Psychically Distant Market. International Business Review, 18(1), 50-5

Olabisi, S.Y., Olagbemi, A.A., \& Atere, A.A. (2013). Factors Affecting Small- Scale Business 'Performance in Informal Economy: A Gendered Based Analysis. Journal of Business and General Education, 5(1), 25-37.

Pittaway, L., Robertson M., Munir, K., Denyer, D., \& Neely, A. (2004). Networking and Innovation: A Systematic Review of the Evidence. International Journal of Management Review, 5-6(3-4): 137168. https://doi.org/10.1111/j.1460-8545.2004.00101

Prashantham, S., \& Dhanaraj, C. (2010). The Dynamic Influence of Social Capital on the International Growth of New Ventures. Journal of Management Studies, 47(6), 967-994. https://doi.org/10.1111/j.1467-6486.2009.00904.x

Provan, K.G., Kimberley, R.I., \& Milward, H. B. (2004). Cooperation and Compromise: A Network Response to Conflicting Institutional Pressures in Community Mental Health. Nonprofit and Voluntary Sector Quarterly, 33, 489-514.

Richard, P. J., Devinney, T.M., George, S.Y., \& Johnson, G. (2009). Measuring Organizational Performance: Towards Methodological Best Practices. Journal of Management, 35(3), 718-804.

Sabina, E.N. (2009). Technology Education: A Panacea to Unemployment in Nigeria. Multidisciplinary Journal of Research Development (MULJORED), 12 (3), 31-37.

Segars, A.H., Grover, V., \& Teng, J. C. (2007). Strategic Information Systems Planning: Planning System Dimensions, Internal Coalignment, and Implications for Planning Effectiveness. Decision Sciences, 29(2), 301-341. https://doi.org/10.1111/j.1540-5915.1998.tb01579

Siwangaza, L., Smit, Y., Bruwer, J., \& Ukpere, W. I. (2014). The Status of Internal Controls in Fast Moving Small Medium and Micro Consumer Goods Enterprises within the Cape Peninsula. Mediterranean Journal of Social Sciences, 5(10), 21-27.

Uzzi, B. (1997). Social Structure and Competition in Interfirm Networks: The Paradox of Embeddedness. Administrative Science Quarterly, 42(1), 35-67. https://doi.org/10.2307/2393808

Waithaka, P. (2016). Moderating Effect of Organizational Factors between Competitive Intelligence Practices and Performance of Firms listed on the Nairobi Securities Exchange, Kenya. European Scientific Journal, ESJ 12 (22), 213-222.

Wright, M., Westhead, P., \& Ucbasaran, D. (2007). The Internationalization of SMEs and International Entrepreneurship: A Critique and Policy Implications. Regional Studies, 41(7), 1013-1030. DOI: $10.1080 / 00343400601120288$

Wynekoopet, J., Johnson, D., \& Finan, J. (2001). Enterprise Network Design: How is it Done? Developing Information System, 1, 87-94. DOI: 10.1007/978-0-387-35489-7_33

Zahra, S.A., Saprienza, H.J., \& Davidson, P. (2006). Entrepreneurship and Dynamic Capabilities: A Review, Model and Research Agenda. Journal of Management Studies, 43 (4), 917-955. 
Zhu, Q., Cordeiro, J., \& Sarkis, J. (2013). Institutional Pressures, Dynamic Capabilities and Environmental Management Systems: Investigating the ISO 9000 - Environmental Management System Implementation Linkage. Journal of Environmental Management, 114, 232-242.

\section{Authors}

The contribution of co-authors is equal and can be expressed as $50 \%$ each of the authors: J. O. Ayegba selected the relevant literature consulted, wrote and edited the literature review carried out while Zhou L. L. Structured the article's Title, sub-headings, Proofread and approved the research.

\section{James Onuche Ayegba}

M.B.A holder in management and PhD candidate in Department of Managements, Faculty of Management and Finance, Jiangsu University, Zhenjiang, Jiangsu province. He specializes in strategic management, small and medium-sized enterprise (SME).

Correspondence to: James Onuche Ayegba, Department of Marketing, Faculty of Management Science and Engineering, Jiangsu University, Zhenjiang Jiangsu province 212013, China, e-mail: 5103150216@stmail.ujs.edu.cn

ORCID (1) http://orcid.org/0000-0001-6127-4353

\section{Zhou Lu Lin}

PhD holder in economics and lecturer at the Department of Health and Economics Management Science and Engineering, Faculty of Management and Finance Professor. Zhou, specializes in Economics and international, economics and actively lectures and researches since 2001.

Correspondence to: zll62@ujs.edu.cn

ORCID (1) http://orcid.org/0000-0002-5266-2191

\section{Acknowledgements and Financial Disclosure}

The article came into being within the project no. 71804061 entitled 'Jiangsu Young Scholars.' financed by National Natural Science Foundation of China (NSFC) conducted by James Onuche Ayegba and Zhou Lu Lin in the year 2020.

The authors would like to thank the anonymous reviewers for their useful comments, which allowed to increase the value of this article.

\section{Copyright and License}

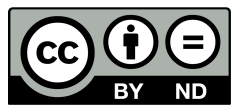

This article is published under the terms of the Creative Commons

Attribution - NoDerivs (CC BY-ND 4.0) License

http://creativecommons.org/licenses/by-nd/4.0/

\section{Published by the Centre for Strategic and International Entrepreneurship - Krakow, Poland}

Ministry of Science and Higher Education Republic of Poland
The journal is co-financed in the years $2019-2020$ by the Ministry of Science and Higher Education of the Republic of Poland in the framework of ministerial programme "Support for Scientific Journals" (WCN) on the basis of contract no. 238/WCN/2019/1 concluded on 15 August 2019. 